\title{
Retroactividad de la Normativa Ambiental
}

\author{
Mario Peña Chacón ${ }^{1}$ \\ Universidad de Costa Rica, San José, Costa Rica
}

(Enviado: Agosto, 2014)

\begin{abstract}
Resumen:
En este documento el autor asume una posición hermenéutica innovadora, estableciendo las bases para la readaptación del principio de la irretroactividad de la ley, cuando éste choca de frente con principios ambientales tales como el de in dubio pro natura, progresividad y no regresividad, tratando así de consolidar la idea de un orden público ambiental, como parte del Estado Social y Ambiental de Derecho.
\end{abstract}

Esta propuesta viene una vez más a denotar la necesidad de flexibilización que la protección del ambiente impone en institutos tradicionales del Derecho, que fueron construidos para una realidad individualista, y no en función de la tutela de intereses colectivos y difusos.

Palabras Claves: irretroactividad de la ley, indubio pro natura, progresividad, no regresividad.

\begin{abstract}
:
In this document the author takes an innovative hermeneutic position, setting the stage for the reconstruction of the principle of non-retroactivity of the law when it clashes with environmental legal principles such as the in dubio pro natura, progressivity and regressivity. This interpretation is a new effort in consolidating the idea of an environmental public order, as part of the Environmental and Social State of Law.

This proposal denotes once again the need for a flexible approach that the protection of the environment imposes on traditional legal institutions, which were built for an individualistic reality, and not to comply with the protection of collective and diffuse interests.

Keywords: retroactivity of the law, indubio pro natura, progressivity, not regressively.

* Este artículo es producto del Proyecto de Investigación denominado "Las clínicas del Derecho Ambiental y Gestión de Riesgos Climáticos a través de una cultura jurídica de la sostenibilidad y no regresión" inscrito ante la Vicerrectoría de Investigación y el Instituto de Investigaciones Jurídicas de la Universidad de Costa Rica bajo el código 722-B3-193.
\end{abstract}

\section{Introducción}

El estatus constitucional y carácter finalista del derecho ambiental obligan al operador jurídico a aplicar las reglas de la norma más favorable y de la condición más beneficiosa para el interés público ambiental. Lo anterior debe hacerse independientemente de su rango o nivel jerárquico, de tratarse de una norma de carácter general o especial, o de su promulgación en el tiempo. Esto se hace porque lo que se busca es precisamente mejorar los niveles de protección mediante la aplicación de la norma más estricta y protectora para el ambiente.

Ahora bien, tratándose de la aplicación de la norma en el tiempo vale cuestionarse: ¿Es posible aplicar de forma retroactiva la normativa ambiental? ¿El principio constitucional de irretroactividad de la ley prohíbe esta posibilidad? ¿Existen derechos adquiridos y

\footnotetext{
${ }^{1}$ Autor para correspondencia. Email: mariopenachacon@gmail.com
} 
situaciones jurídicas consolidadas cuando está de por medio un derecho de incidencia colectiva como lo es el de gozar de un ambiente sano y ecológicamente equilibrado?

El presente ensayo pretende dar respuesta a estas interrogantes aplicando las reglas de la hermenéutica ambiental, identificando aquellos supuestos donde es posible e incluso necesaria la aplicación retroactiva de la norma ambiental.

\section{Principio de irretroactividad de la ley}

El artículo 34 constitucional prohíbe la aplicación retroactiva de las normas jurídicas en aquellas situaciones donde se perjudique al administrado, al efecto dispone:

"A ninguna ley se le dará efecto retroactivo en perjuicio de persona alguna, o de sus derechos patrimoniales adquiridos o de situaciones jurídicas consolidadas."

En virtud de esta disposición constitucional, ningún acto administrativo o disposición normativa puede afectar o proyectar sus efectos sobre el pasado, concretamente respecto de situaciones de hecho o situaciones jurídicas consolidadas o derechos patrimoniales adquiridos.

Se está ante una situación de retroactividad cuando la norma nueva se aplica a un supuesto de hecho ya acaecido y consumado en un momento anterior al de su entrada en vigencia, quedando prohibida la incidencia de la nueva normativa en los efectos jurídicos ya producidos en situaciones anteriores.

Se trata de un principio que resulta de aplicación a toda la legislación, salvo casos excepcionales, ${ }^{2}$ de manera que resulta de obligado acatamiento respecto de todas las normas jurídicas en general y no únicamente de las leyes de carácter formal. ${ }^{3}$

El artículo 34 constitucional no prohíbe irrestrictamente la retroactividad, sino únicamente aquella que pretende interferir con derechos patrimoniales adquiridos y situaciones jurídicas consolidadas, nacidas con anterioridad a la promulgación de la ley, o sea, aquellas con características de validez y eficacia perfeccionadas bajo el imperio de otras regulaciones, de forma que sus efectos y consecuencias no pueden ser variadas por nuevas disposiciones, excepto si conllevan beneficio para los interesados. ${ }^{4}$

Ha sido la jurisprudencia constitucional la que ha definido los alcances del principio constitucional de irretroactividad de la ley, dejando claro que no consiste en un derecho a que el ordenamiento jurídico se mantenga petrificado, invariable, incólume o inmutable. ${ }^{5}$ En la sentencia 2007-2765 la Sala Constitucional planteó así la distinción:

"En este caso, la garantía constitucional de la irretroactividad de la ley se traduce en la certidumbre de que un cambio en el ordenamiento no puede tener la consecuencia de

\footnotetext{
2 Como excepciones se tiene la materia penal, cuando la nueva norma sustantiva es más favorable al imputado; materia laboral a favor del trabajador y como se verá más adelante en materia ambiental donde aplica la regla de la norma más favorable al interés público ambiental.

${ }^{3}$ En ese sentido, consultar las sentencias constitucionales 2001-00618 y 1996-7043.

${ }^{4}$ Sentencia constitucional número 1996-7046.

5 Sentencia constitucional 2008-01569.
} 
sustraer el bien o el derecho ya adquirido del patrimonio de la persona, o de provocar que si se había dado el presupuesto fáctico con anterioridad a la reforma legal, ya no surja la consecuencia (provechosa, se entiende) que el interesado esperaba de la situación jurídica consolidada. Ahora bien, específicamente en punto a ésta última, se ha entendido también que nadie tiene un 'derecho a la inmutabilidad del ordenamiento', es decir, a que las reglas nunca cambien”.

En esa misma línea jurisprudencial el voto constitucional 2006-13330 dispuso:

"Sin embargo, se advierte, que en aplicación de este precepto constitucional, no se genera un 'derecho a la inmutabilidad del ordenamiento', de manera que en modo alguno puede pretenderse la inmodificación del ordenamiento jurídico; con lo cual, no puede aspirarse a que una vez nacida a la vida jurídica, la regla que conecta el hecho con el efecto se mantenga, en tanto la misma puede ser modificada o incluso suprimida por norma posterior; sino -como se explicó- que si se ha producido el supuesto condicionante, una reforma normativa que cambie o elimine la regla no podrá tener la virtud de impedir que surja el efecto condicionado que se esperaba bajo el imperio de la norma anterior. Y esto es así porque, como se dijo, lo relevante es que el estado de cosas de que gozaba la persona y a estaba definido en cuanto a sus elementos y a sus efectos, aunque éstos todavía se estén produciendo o, incluso, no hayan comenzado a producirse. De este modo, a lo que la persona tiene derecho es a la consecuencia, no a la regla".

La regla constitucional de la irretroactividad de las normas opera únicamente cuando el legislador ignora o desconoce los efectos consolidados de situaciones jurídicas anteriores a la norma, pero no así sobre los efectos futuros de tales situaciones. Al respecto cabe citar el voto constitucional 2007-4746:

"Del texto transcrito se tiene que en Costa Rica, el constituyente ha previsto la posibilidad de que las normas sean aplicadas incluso a casos anteriores a su entrada en vigencia, siempre y cuando dicha aplicación retroactiva no lesione derechos subjetivos o situaciones jurídicas consolidadas, procurando garantizar seguridad jurídica a las personas, de manera que cambios en el ordenamiento jurídico no impliquen una afectación de situaciones amparadas en las normas precedentes. Dicho principio constitucional informa todo el ordenamiento jurídico y tiende a que los administrados estén en condiciones de saber cuáles actividades pueden llevar a cabo y cuáles no, y las consecuencias de dichos comportamientos u omisiones. Propiamente en el plano de la normatividad administrativa, la regla consagrada en el artículo 34 constitucional implica que los actos administrativos y las situaciones jurídicas consolidadas a favor de los administrados, no pueden ser revocadas unilateralmente en virtud de una disposición posterior, excepto si se siguen los rigurosos trámites para ello previstos y, si es el caso, se obliga a la Administración a indemnizar por los daños que una actuación legítima suya cause en una persona o grupo específico de éstas. Es claro que la Administración no queda eternamente sujeta a las reglas que dicta, pues siempre le cabe la posibilidad de revocar dichas normas y sustituirlas por otras más acordes con la realidad actual y que de mejor forma contribuyan a lograr su fin esencial: satisfacer el interés general. Por ello, la modificación reglamentaria de los requisitos o condiciones en que puede ser llevada a cabo una actividad por parte de los administrados es válida, e incluso su 
aplicación retroactiva lo es, a menos que -como se dijo- ello provoque el desconocimiento de derechos subjetivos o situaciones jurídicas consolidadas”.

A pesar que la Constitución Política establece como límites a la aplicación retroactiva de las normas los "derechos adquiridos" y las "situaciones jurídicas consolidadas", no llega a definirlos, razón por la cual es necesario acudir a la propia jurisprudencia constitucional para lograr determinar y delimitar su significado y alcances:

"Es dable afirmar que, en términos generales, el primero -derecho adquirido-denota a aquella circunstancia consumada en la que una cosa-material o inmaterial, trátese de un bien previamente ajeno o de un derecho antes inexistente- ha ingresado en (o incidido sobre) la esfera patrimonial de la persona, de manera que ésta experimenta una ventaja o beneficio constatable. Por su parte, la «situación jurídica consolidada» representa no tanto un plus patrimonial, sino un estado de cosas definido plenamente en cuanto a sus características jurídicas y a sus efectos, aun cuando éstos no se hayan extinguido aún. Lo relevante en cuanto a la situación jurídica consolidada, precisamente, no es que esos efectos todavía perduren o no, sino que -por virtud de mandato legal o de una sentencia que así lo haya declarado- haya surgido ya a la vida jurídica una regla, clara y definida, que conecta a un presupuesto fáctico (hecho condicionante) con una consecuencia dada (efecto condicionado). Desde esta óptica, la situación de la persona viene dada por una proposición lógica del tipo «si..., entonces...»; vale decir: si se ha dado el hecho condicionante, entonces la "situación jurídica consolidada" implica que, necesariamente, deberá darse también el efecto condicionado." (Voto constitucional número 1997-02765, de las quince horas con tres minutos del veinte de mayo de mil novecientos noventa y siete).

Una vez expuesto de forma somera los alcances, límites y restricciones del principio constitucional de irretroactividad de la ley, corresponde cuestionarse su aplicación frente a los derechos de incidencia colectiva de carácter ambiental.

\section{Inexistencia de derechos adquiridos y situaciones jurídicas consolidadas en materia ambiental}

Por tratarse de un derecho humano y además, normativa de orden público ${ }^{6}$, y por tanto de aplicación obligatoria e inmediata, la jurisprudencia constitucional ha sido constante en considerar que en materia ambiental y de preservación de los derechos a la salud, a la vida y la seguridad de las personas, no es posible considerar la existencia de derechos adquiridos ni de situaciones jurídicas consolidadas. ${ }^{7}$

\footnotetext{
6 “....es claro que la autorización previa de la municipalidad no puede estimarse como una excepción de la aplicación de la normativa y exigencias ambientales, toda vez que las mismas son de orden público, en tanto derivan de la obligación constitucional que se impone al Estado - en un sentido amplio e integralde la tutela ambiental, y el correlativo derecho de todas las personas a tener un ambiente sano y ecológicamente equilibrado, como derivado directo del artículo 50 constitucional, lo que las hace de acatamiento obligatorio, y no puede excepcionarse su aplicación bajo ningún supuesto, en tanto son expresión del principio constitucional ambiental de la utilización racional de los elementos y recursos que conforman el ambiente". Sentencia constitucional número 2006-13330.
}

7 Al respecto ver las sentencias constitucionales 2004-14576 y 1993-2742, entre otras. 
La Sala Constitucional ha reiterado que la protección y preservación de la integridad del medio ambiente natural es un derecho fundamental, de modo que frente a los intereses particulares, prevalece sin duda alguna, el derecho a disfrutar de un ambiente sano y ecológicamente equilibrado. Por lo anterior, estando de por medio el ambiente y la salud y por tratarse de normativa de orden público, la aplicación inmediata de la norma que tiene como fin su tutela y protección se impone por sobre otro tipo de normativa (comercial - industrial) que no gozan de dicho rango. ${ }^{8}$

De esta forma, no es posible alegar la existencia de derechos adquiridos ni de situaciones jurídicas consolidadas cuando estos se encuentran en contraposición del derecho fundamental al ambiente sano y ecológicamente equilibrado. Cuando un derecho presuntamente adquirido se enfrenta a un derecho de incidencia colectiva de carácter ambiental; si el primero pone en peligro la conservación o sostenibilidad del segundo, la Constitución Política protege y hace prevalecer el derecho fundamental al ambiente, en virtud de los posibles daños de difícil o imposible reparación.

En múltiples ocasiones el Tribunal Constitucional ha anulado actos declarativos de derechos otorgados a particulares, por ser violatorios al derecho fundamental al ambiente sano y ecológicamente equilibrado, incluso por la vía procesal del recurso de amparo, donde naturalmente y de haberlos, la sentencia también debe respetar derechos adquiridos legítimamente.

En respaldo de lo anterior, y a manera de ejemplos es posible citar el voto constitucional 2008-18529 que anuló todos los permisos de construcción otorgados a propiedades ubicadas dentro de la zona de amortiguamiento (banda de 500 metros) del Parque Nacional Marino Las Baulas sin que tuvieran las viabilidades ambientales; y en materia de protección de acuíferos, la sentencia constitucional 2004-1923 que anuló los permisos municipales y demás autorizaciones donde particulares contaban con viabilidad ambiental expedida por la Secretaría Técnica Nacional Ambiental.

Este mismo criterio también ha sido aplicado a situaciones patrimoniales consolidadas, incluso interlocutoriamente; tales como madera talada al amparo de actos anulados por violar el derecho al ambiente que la Sala Constitucional no ha permitido siquiera la movilización ni aprovechamiento alguno por parte de los permisionarios de una explotación forestal. ${ }^{9}$

Partiendo de la existencia de un orden público ambiental, propio de un Estado Social y Ambiental de Derecho, donde el interés público ambiental, por regla general, prevalece por sobre los intereses particulares, los derechos adquiridos y situaciones jurídicas consolidadas no encuentran cabida cuando entran en conflicto y puedan afectar los derechos ambientales de incidencia colectiva; situación que en nada obstaculiza la posibilidad del respectivo reclamo de los posibles daños y perjuicios ocasionados.

\footnotetext{
${ }^{8}$ Ver dictamen número C-2-2010 de la Procuraduría General de la República.

${ }^{9}$ Sentencia constitucional número 2002-6446 y su aclaración y adición: voto 2003-02862.
} 
Es posible afirmar entonces que nadie tiene el derecho adquirido a contaminar ni puede alegar la existencia de una situación jurídica consolidada cuando además estén de por medio intereses colectivos ambientales.

\section{Retroactividad de la normativa ambiental}

El estatus constitucional y carácter finalista del derecho ambiental, así como los principios protectores, in dubio pro natura, progresividad, y no regresividad, obligan al operador jurídico a aplicar las reglas de la norma más favorable y de la condición más beneficiosa para el interés público ambiental. Lo anterior independientemente de su rango o nivel jerárquico, de tratarse de una norma de carácter general o especial, o de su promulgación en el tiempo.

En cuanto a este último aspecto, en virtud del principio de progresividad, la norma ambiental posterior debe ser más rigurosa que la promulgada con anterioridad, y por tanto, debe descartarse la regla de "lex posterior derogat priori", en la medida que lo que se busca es precisamente mejorar los niveles de protección mediante la aplicación de la norma más estricta y protectora para el ambiente.

Bajo esta lógica es absolutamente posible, e incluso en ocasiones necesaria, la aplicación retroactiva de la normativa ambiental, en la medida que esto conlleve mayores niveles de protección.

A continuación se expondrán, a manera de ejemplo, dos distintas situaciones donde se justifica la aplicación retroactiva de las normas ambientales.

\subsection{Licencias ambientales}

El profesor JORDANO FRAGA ${ }^{10}$ nos recuerda que de conformidad con la jurisprudencia española en materia de licencias de actividad no existen derechos adquiridos; ${ }^{11}$ que sin licencia no hay derecho adquirido ${ }^{12}$ y que las licencias ambientales como actos-condición no generan derechos adquiridos a contaminar debiendo adaptarse a la legislación ambiental que se vaya dictando. ${ }^{13}$

Señala este ilustre jurista español que las normas ambientales habitualmente miran al futuro (por ejemplo se someten a Evaluación de Impacto Ambiental las futuras actividades que se implanten), pero cada vez es más usual que también contemplen el pasado desde la premisa que nadie tiene ganado el derecho adquirido a contaminar (si se amplían actividades existentes o se trasladan habrán de someterse a Evaluación de Impacto Ambiental). Suele afirmarse en este sentido que las autorizaciones ambientales son actos condiciones con rebus sic stantibus incorporado. Muchas veces las normas llevan esa cláusula de progreso clásica de los servicios públicos, normalmente formulada en el derecho ambiental como Best Available Technnology (B.A.T). El Estado social

\footnotetext{
${ }^{10}$ Jordano Fraga, Jesús, El Derecho Ambiental del siglo XXI, Medio Ambiente \& Derecho, Revista de Derecho Ambiental de la Universidad de Sevilla, número 09, julio 2003, España.

${ }^{11}$ STS de 22 de julio de 1996, Ar. 1996/6203

12 STS de 23 de marzo de 1992. Ar. 1992/3229

13 STSJ de Andalucía de 9 de febrero de 1999, RJCA 1999\371, Sala en Sevilla de lo ContenciosoAdministrativo, Sección 2, y STSJ de Andalucía, de 1 de diciembre de 1999, RJCA 1999\4772, Sala en Málaga de lo Contencioso-Administrativo.
} 
lleva implícito ese poder transformador, pues de otro modo, ese deber de transformación de la sociedad (deber que España ostenta rango constitucional) sería de imposible realización. ${ }^{14}$

Por su parte, VALLS hace mención que la doctrina argentina viene citando desde hace más de un siglo el histórico fallo de la Corte Suprema de Justicia de Argentina CXVIII, 278 y XXXI, 23, Podestá, Santiago y otros c/ Provincia de Buenos Aires s/ indemnización de daños y perjuicios, de fecha 14 de mayo de 1887, que faculta aplicar la norma ambiental a situaciones creadas, sin violentar el principio de retroactividad, fundado en el deber de proteger la salud pública contra la cual no existen derechos adquiridos. ${ }^{15}$

La situación en Costa Rica es similar a los casos antes citados de España y Argentina. La jurisprudencia constitucional admite la aplicación de nueva normativa, y por consiguiente de nuevos requisitos en materia de salud y ambiente, respecto de actividades, obras y proyectos que operan desde antes de la entrada en vigencia de tales normas. En ese sentido la sentencia 2004-14576 dispuso:

"Al respecto, estima la Sala que a pesar de que efectivamente se le está exigiendo al recurrente el cumplimiento de algunos requisitos que no fueron solicitados por la Administración años atrás, lo cierto del caso es que, por encontrarse de por medio el interés público de proteger la salud, la vida, la seguridad de las personas y el ambiente, no puede considerarse válido el argumento del recurrente en el sentido de que por tener veinte años de operar ahí puede continuar haciéndolo ya que precisamente la exigencia de esas nuevas condiciones y requisitos, tiende a preservar el ambiente y a garantizar el derecho a la salud, a la vida y a la seguridad de las personas que habitan en el lugar que es una zona residencial. En ese sentido y como en otras ocasiones se ha afirmado, estima

\footnotetext{
${ }^{14}$ Jordano Fraga, Jesús, El Derecho Ambiental del siglo XXI, Medio Ambiente \& Derecho, Revista de Derecho Ambiental de la Universidad de Sevilla, número 09, julio 2003, España.

15 SUMARIO: Código Civil, art. 2611. Leyes de la Provincia de Buenos Aires del 31 de mayo de 1822 y de 6 de septiembre de 1881. Ley 13, Título 32, Partida 3․ DOCTRINA DEL FALLO: Antecedentes: Los saladeristas de Barracas demandaron a la Provincia de Buenos Aires por la indemnización de los daños y perjuicios que les ha causado la suspensión de las faenas de los saladeros situados en el Riachuelo de Barracas ordenada por la ley de la Provincia de Buenos Aires del 6 de septiembre de 1881. Doctrina: "Que por ellas (N. del A: se refiere a las disposiciones administrativas sobre saladeros dictadas hasta la fecha de la ley que motiva el juicio), no se acuerda a los demandantes ningún derecho irrevocable para establecer sus saladeros en el Riachuelo de Barracas, pues se limitan a reglamentar esta industria, prescribiendo las condiciones higiénicas a que debe sujetarse y aun suspendiendo el ejercicio de ella en aquel punto, cuando la salud pública ha hecho necesaria esta medida". "Que la autorización de un establecimiento industrial está siempre fundada en la presunción de su inocuidad, y no obliga al Gobierno que la concedió, cuando esta presunción ha sido destruida, por los hechos, pues en tal caso, el deber que sobre él pesa de proteger la salud pública contra la cual no hay derechos adquiridos, recobra toda su fuerza y no solamente puede imponer el establecimiento nuevas condiciones, sino retirar la autorización concedida, si estas no se cumplieran o fuesen ineficaces para hacerlos totalmente inocuos". "Que la objeción que hoy se opone a la ley y decreto citados, de ser contrarios a la Constitución y a las leyes civiles, por cuanto atacan la propiedad y el ejercicio de una industria lícita, no tiene fundamento alguno legal, porque según la Constitución, esos derechos están sujetos a las leyes que reglamenten su ejercicio, y según nuestro Código Civil, la propiedad está sujeta a las restricciones y limitaciones exigidas por el interés público o por el interés privado correspondiente (arts. 2611 del Código Civil)".
} 
la Sala que tratándose de materia ambiental y de la preservación de los derechos a la salud, a la vida o la seguridad de las personas, no solo no puede considerarse la existencia de derechos adquiridos sino que, además, el Estado siempre cuenta con la posibilidad de exigir el cumplimiento de nuevos requisitos a las diferentes actividades que desarrollen los individuos, aun cuando el inmueble o el tipo de labor que se realiza, sea anterior a la modificación de la ley que exige nuevas condiciones. Debe recordarse que esta Sala en cuanto al ambiente se refiere, ha manifestado que la protección y preservación de la integridad del medio ambiente natural es un derecho fundamental, de modo que frente al interés particular de un individuo a desarrollar una actividad, prevalecerá sin duda alguna, el derecho a disfrutar de un ambiente sano y ecológicamente equilibrado; derecho éste que también le concierne a aquél individuo. A partir de lo dicho entonces, estima la Sala que el recurrente no puede alegar que ha derivado derechos adquiridos por haber disfrutado del ejercicio de una actividad que ahora no se ajusta a derecho y por el hecho de que no le hubieran exigido en el pasado el cumplimiento de determinados requisitos, pues el interés público representado por el Estado en cuanto a su obligación de velar por el derecho que le asiste a toda persona de gozar de un ambiente sano y ecológicamente equilibrado así como también del derecho a la vida, a la salud o a la seguridad de las personas predomina sobre el interés privado de la explotación de la actividad de parqueo de cisternas que se ha estado desarrollando en una zona que en la actualidad no reúne las condiciones para ese tipo de labores, sobre todo si se toma en cuenta que, en todo caso, la actividad no cuenta con permiso sanitario de funcionamiento ni tampoco con patente municipal por lo que es evidente que el ejercicio de esa actividad ha estado al margen del ordenamiento jurídico. Ahora bien, como consecuencia de lo anterior, en caso de que la actividad deba ser clausurada con fundamento en las anteriores consideraciones, el individuo siempre cuenta con la posibilidad de que se le indemnice cuando ello sea procedente, lo cual, en todo caso, deberá ser determinado por la autoridad competente por cuanto se refiere a un aspecto de legalidad. En consecuencia, este Tribunal considera que en la especie no se ha producido la violación alegada por la parte recurrente en concordancia con las consideraciones anteriormente señaladas".

En un sentido similar, en el voto número 2006-4746 la Sala Constitucional dejó claro que la modificación de los requisitos o condiciones en que puede ser llevada a cabo una actividad por parte de los administrados es válida, e incluso su aplicación retroactiva lo es, a menos que ello provoque el desconocimiento de derechos subjetivos o situaciones jurídicas consolidadas. De este fallo es posible destacar el siguiente extracto:

"Precisamente, en materia de salud pública los permisos son otorgados por períodos cortos con la intención de que el control que ejerza el Estado (a través del Ministerio de Salud) de las actividades potencialmente lesivas de la salud pública, sea un control constante y efectivo. Al acudir la amparada a solicitar prórroga de su permiso, en el fondo lo que hizo fue requerir una nueva licencia, por lo que en ese momento la Administración no solo podía, sino que además debía, exigirle el cumplimiento de toda la normativa vigente a la fecha de su nueva solicitud. En razón de lo anterior, esta Sala estima que en la especie no ha ocurrido una aplicación de las normas referidas contraria a la regla contenida en el artículo 34 constitucional, sin perjuicio de la posibilidad que conserva la amparada de acudir a la vía administrativa o a la jurisdicción común a 
reclamar en caso de que considere encontrarse ante un supuesto de responsabilidad por actividad lícita de la Administración, prevista en los artículos 194 y 195 de la Ley General de la Administración Pública”.

La jurisprudencia constitucional reconoce el poder-deber de la Administración de exigir el cumplimiento de nuevos requisitos a las diferentes actividades en aras de preservar los derechos de incidencia colectiva, sin que sea relevante la fecha en que ha iniciado la actividad, obra o proyecto de que se trate. Este ha sido el criterio sostenido por la Sala Constitucional a partir de la resolución 1993-2742:

"Del informe rendido -que se tiene dado bajo juramento- y de la documentación a él acompañada se desprende que la nueva orden de desalojo emitida por el codemandado Inspector Sanitario de Curridabat, de conformidad con lo ordenado en resolución $\mathrm{N}^{\circ} \mathrm{DM}$ 1544-92 -de lo que se reclama-, se basa no sólo en el incumplimiento de parte de la empresa recurrente de anteriores Órdenes Sanitarias para que evacuaran sanitariamente las aguas pluviales y desechos sólidos (aceites) de su propiedad para evitar filtraciones a las propiedades de sus vecinos -de lo que éstos se quejaban- y para proteger la Salud Pública, sino en el hecho de operar sin el debido Permiso Sanitario de Funcionamiento, que tenía que solicitar al Departamento de Ingeniería Sanitaria lo cual se negó a hacer pese a la advertencia en tal sentido se le hizo desde el ocho de agosto de mil novecientos ochenta y ocho por medio de la Orden Sanitaria $\mathrm{N}^{\circ} 17343-\mathrm{A}-$, sin que pueda alegarse como se pretende que la Ley General de Salud entró en vigencia con posterioridad a la construcción y operación de las instalaciones de la recurrente por lo que ésta tenía derechos adquiridos, pues no sólo dicha ley es de orden público y, por ende, oponible a los intereses particulares, sino que en detrimento de la salud pública no existen derechos adquiridos no situaciones jurídicas consolidadas, de manera tal que toda empresa debe adecuar sus instalaciones y funcionamiento a las disposiciones que en esta materia establezca el Estado, sin importar -como en este caso- que aquella haya estado operando antes de la entrada en vigencia de la nueva normativa, a la que en todo caso, deberá adecuarse dentro de un plazo razonable. De modo que lo actuado por los recurridos no resulta arbitrario, pues además de serlo dentro del ámbito de las facultades y competencias otorgadas por la Ley, lo fue para poner a derecho una situación irregular, situación que no remedió la recurrente a pesar de habérsele otorgado al efecto un plazo más que suficiente...".

De las votos antes expuestos se deduce la inexistencia de derechos adquiridos en materia de licencias y permisos ambientales, siendo que todo tipo de actividades, obras o proyectos en ejecución deben ir adaptándose a la legislación ambiental que se vaya promulgando en el tiempo, normativa que a raíz del principio de progresividad, debe ser cada vez más estricta buscando "proteger más" y "contaminar menos".

Debe tenerse claro que la prohibición de retroactividad contenida en el numeral 34 constitucional no se encuentra en contraposición con el poder-deber conferido a la Administración Pública de velar de modo continuado y progresivo por el cumplimiento del orden público ambiental, por ello ante el incumplimiento de las prevenciones ambientales reglamentarias exigibles a cualquier tipo de concesión o licencia para explotación de una determinada actividad, obra o proyecto que pueda ser calificada de peligrosa, nociva o molesta para el ambiente o la salud, o bien, el riesgo o la constatación 
de una situación de peligro sobrevenido, justifican e imponen una actuación de fiscalización preventiva por parte de las autoridades competentes, que puede llegar a hacer cesar la actividad originariamente permisible e incluso cancelar la concesión otorgada.

\subsection{Ordenamiento territorial}

El ordenamiento territorial es la expresión espacial de las políticas sociales, ambientales y económicas. Es también un ejercicio administrativo y una política de Estado, basada en la toma de decisiones coordinadas y articuladas, con el fin de garantizar un desarrollo adecuado de los asentamientos humanos, la gestión integral de los recursos naturales y el desarrollo económico en el territorio. ${ }^{16}$

Por su parte, Plan Regulador según la Ley de Planificación Urbana, es el instrumento de planificación local que define en un conjunto de planos, mapas, reglamentos y cualquier otro documento, gráfico o suplemento, la política de desarrollo y los planes para distribución de la población, usos de la tierra, vías de circulación, servicios públicos, facilidades comunales, y construcción, conservación y rehabilitación de áreas urbanas.

La jurisprudencia constitucional ha entendido por plan regulador: "mecanismos amplios de planificación por medio de los cuales, los gobiernos locales deciden acerca del mejor uso que debe ser dado a la tierra, así como al diseño de los servicios públicos, vías locales de comunicación, vivienda y renovación urbana, entre otros. En tal sentido, estos planes constituyen mecanismos de política municipal que permiten planificar el tipo de desarrollo que se desea para cada cantón, en atención de los derechos e intereses de sus habitantes y de los valores de rango constitucional que informan toda actuación pública" (Voto número 2007-9120).

La Sala Constitucional en el voto número 2006-13330 estimó que los planes reguladores locales por su contenido, eficacia y obligatoriedad general, son "verdaderas normas jurídicas o leyes en sentido material, toda vez que reconoce derechos y establece obligaciones para los titulares y poseedores de los inmuebles ubicados en la circunscripción territorial del respectivo cantón".

Tratándose por tanto de normas jurídicas en sentido formal, los planes reguladores no podrían, bajo ningún motivo quedar exento de la aplicación del principio de irretroactividad de la ley.

De esta forma, los planes de ordenamiento territorial, una vez promulgados, surten efectos hacia futuro, debiéndose resguardar todas aquellas situaciones jurídicas consolidadas y derechos adquiridos con anterioridad a su entrada en vigencia. De ahí que toda actividad, obra o proyecto desarrollado con antelación y que se encuentre en operación, conserva el estatus obtenido (uso de suelo) bajo la anterior normativa, no obstante la posible disconformidad posterior establecida mediante el nuevo plan de ordenamiento territorio,

\footnotetext{
${ }^{16}$ Definición contenida en la Política Nacional de Ordenamiento Territorial (PNOT) 2012-2014, oficializada por medio del decreto ejecutivo número 37623-PLAN-MINAET-MIVAH publicado en el Diario Oficial La Gaceta número 89 del 10 de mayo de 2013.
} 
en la medida que constituye una situación jurídica consolidada que calificaría tácitamente como una "autorización de un uso no conforme".

Ahora bien, no resulta posible la aprobación de actividades, obras o proyectos que califiquen como de nuevas y que sean contrarias al plan de ordenamiento territorial vigente, no obstante hubieran sido aprobadas inicialmente a la luz de la anterior normativa, siendo imposible alegar en este supuesto, la existencia de derechos adquiridos, rigiendo en forma absoluta las nuevas normas ambientales y urbanísticas las cuales despliegan sus efectos sobre situaciones realizadas con antelación a su puesta en vigencia.

Además, la autorización previa de uso de suelo no puede estimarse como una excepción de la aplicación de la normativa y exigencias ambientales, toda vez que las mismas son de orden público, en tanto derivan de la obligación constitucional que se impone al Estado -en un sentido amplio e integral- de la tutela ambiental, y el correlativo derecho de todas las personas a tener un ambiente sano y ecológicamente equilibrado, como derivado directo del artículo 50 constitucional, lo que las hace de acatamiento obligatorio, y no puede quedar exenta su aplicación bajo ningún supuesto, en tanto son expresión del principio constitucional ambiental de la utilización racional de los elementos y recursos que conforman el ambiente. ${ }^{17}$

\subsection{Sitios contaminados}

Como es bien sabido, la contaminación de suelos por actividades industriales o de otra naturaleza (industriales, comerciales, de servicios, actividades agropecuarias o agroindustriales) suele producirse en largos periodos de tiempo y cuando esto ocurre, existe la obligación de saneamiento y recomposición, responsabilidad de carácter objetiva que recae generalmente sobre el tenedor actual del terreno contaminado, y que incluye los daños acaecidos en virtud de todas aquellas actividades realizadas sin su conocimiento, o bien con anterioridad a la adquisición del inmueble contaminado.

En el derecho comparado la norma de referencia respecto a la responsabilidad por suelos contaminados es la Comprehensive Environmental Response, Compensation, and Liability Act (CERCLA) de los Estados Unidos, la cual en su sección 107 establece expresamente la retroactividad de sus efectos normativos. En la jurisprudencia norteamericana varios fallos descartan que la aplicación retroactiva de la CERCLA violente las reglas del due process al establecer la responsabilidad de saneamiento de sitios contaminados por conductas acontecidas antes de la aprobación de la CERCLA. ${ }^{18}$

En el caso costarricense se cuenta actualmente con el decreto ejecutivo 37757-S publicado en la Gaceta número 132 del 10 de julio de 2013 - Reglamento sobre Valores guía en suelos para descontaminación de sitios afectados por emergencias ambientales y derrames - el cual establece el listado de sustancias químicas y los valores guía a partir de los cuales se podrían provocar alteraciones perjudiciales a la calidad del suelo, a fin de evitar daños a la salud pública y al ambiente; así como los procedimientos administrativos para la gestión del riesgo en casos de contaminación de suelo y medios con los que éste

\footnotetext{
${ }^{17}$ Sentencia constitucional número 2006-13330.

${ }^{18} \mathrm{Al}$ respecto ver United States v. South Carolina Recycling \& Disposal, Inc., 653 f. .Supp 9848 D.S.C 1984; Northeastern Pharmaceutical \& Chemical Co., Inc 810 F. 2d 726 (8 Cir. 1986); State of New York v. Shore Realty Corp, 759 F. 2d 1032 (2d Cir. 1985).
} 
tenga contacto, incluyendo una serie de reglas especiales respecto a la responsabilidad por daño ambiental y el consecuente deber de saneamiento de suelos en situaciones relativas a sitios contaminados abandonados, donaciones y transferencias de inmuebles contaminados, cambios de uso de suelo y situaciones de contaminación en sitios ocupados trazable a ocupantes anteriores o actividades externas.

Debe tenerse presente que en materia de suelos contaminados se parte de la hipótesis de la persistencia de la polución y de sus potenciales efectos nocivos, por ello el acto declarativo de sitio contaminado, así como la obligación de saneamiento, subsisten mientras sigan activos los productos o sustancias depositadas en el inmueble contaminado, independientemente de la época en que éstos fueron introducidos.

Ahora bien, partiendo del hecho de que el ordenamiento jurídico costarricense permite la aplicación retroactiva de la normativa ambiental, y tomando en cuenta que no existe el derecho adquirido a contaminar el suelo con peligro para el ambiente y la salud de las presentes y futuras generaciones, el reglamento sobre contaminación de suelos antes citado puede y debe aplicarse a situaciones acontecidas con anterioridad a su puesta en vigencia, en la medida que la recomposición del ambiente es una obligación constitucional preexistente a la puesta en vigencia del reglamento de rito, sustentada en el numeral 50 constitucional que contiene el deber estatal y de los particulares de garantizar, defender y preservar el derecho a un ambiente sano y ecológicamente equilibrado y de fijar las responsabilidades y las sanciones correspondientes, reforzada además, entre otras, por la Ley Orgánica del Ambiente de 1995 como en la Ley de Uso, Manejo y Conservación de Suelos del año 1998, y la Ley de Gestión Integral de Residuos del 2010.

En este sentido coincidimos plenamente con JORDANO FRAGA en cuanto a que si se afirma ex novo el deber de descontaminar suelos no se está creando ex novo la responsabilidad con carácter retroactivo, sino especificando un procedimiento en el que se otorgan poderes a la Administración (con la eventual supervisión, en su caso, de los tribunales). ${ }^{19}$

Con el fin de responder las interrogantes expuestas en la parte introductoria de este artículo, y a manera de conclusión, puede afirmarse que en virtud de la inexistencia de derechos patrimoniales adquiridos y de situaciones jurídicas consolidadas frente a derechos de incidencia colectiva, es posible y en ocasiones necesaria, la aplicación retroactiva de la normativa ambiental sin que ello violente el principio contenido en el numeral 34 constitucional.

\section{Bibliografía}

Baño León, José María, Los suelos contaminados: obligación de saneamiento y derecho de propiedad, en Revista Aranzadi de Derecho Ambiental, número 02, 2002.

Franco, Horacio J., Pasivos Ambientales y realidad económica, en Revista Derecho Ambiental, Abeledo Perrot, número 33, 2013.

\footnotetext{
${ }^{19}$ Jordano Fraga, Jesús, El Derecho Ambiental del siglo XXI, Medio Ambiente \& Derecho, Revista de Derecho Ambiental de la Universidad de Sevilla, número 09, julio 2003, España.
} 
Jordano Fraga, Jesús, El Derecho Ambiental del siglo XXI, Medio Ambiente \& Derecho, Revista de Derecho Ambiental de la Universidad de Sevilla, número 09, julio 2003.

Peña Chacón, Mario, Los derechos adquiridos de buena fe y sus implicaciones ambientales, en Revista Monfrague, Desarrollo Resiliente, volumen II, número 1, enero 2014, accesible en: http://monfragueresiliente.com/numero3/indice3.html

Peña Chacón, Mario, Hacia una nueva hermenéutica ambiental, en Lex, Difusión y Análisis, año XII, , número 222, México, diciembre 2013.

Peña Chacon, Mario, Aplicación de la regla de la norma más favorable, en Biblioteca Jurídica digital Maestría Derecho Ambiental, Universidad de Costa Rica, enero 2014, accesible en: http://maestriaderechoambientalucr.files.wordpress.com/2014/ 01/aplicacic3b3n-de-la-regla-de-la-norma-mc3a1 s- favorable-en-el-derecho-ambie ntal-1.pdf

Valls, Mario Francisco, Derecho Ambiental, Iera Edición, Buenos Aires, Abeledo Perrot, 2008.

\section{"LA REVISTA INNOVARE NO SE HACE RESPONSABLE EN NINGÚN CASO DE LOS CONTENIDOS, DATOS, CONCLUSIONES U OPINIONES VERTIDAS EN LOS ARTÍCULOS PUBLICADOS, SIENDO ESTA RESPOSABILIDAD EXCLUSIVA DEL (DE LOS) AUTOR (AUTORES)"}

